\title{
The Lifetime Costs and Benefits of Medical Technology
}

\section{Citation}

Cutler, David. The lifetime costs and benefits of medical technology. 2007. Journal of Health Economics 26, no. 6: 1081-1100.

\section{Published Version}

http://dx.doi.org/10.1016/j.jhealeco.2007.09.003

\section{Permanent link}

http://nrs.harvard.edu/urn-3:HUL.InstRepos:2643640

\section{Terms of Use}

This article was downloaded from Harvard University's DASH repository, and is made available under the terms and conditions applicable to Other Posted Material, as set forth at http:// nrs.harvard.edu/urn-3:HUL.InstRepos:dash.current.terms-of-use\#LAA

\section{Share Your Story}

The Harvard community has made this article openly available.

Please share how this access benefits you. Submit a story.

\section{Accessibility}


NBER WORKING PAPER SERIES

THE LIFETIME COSTS AND BENEFITS OF MEDICAL TECHNOLOGY

\author{
David M. Cutler \\ Working Paper 13478 \\ http://www.nber.org/papers/w13478 \\ NATIONAL BUREAU OF ECONOMIC RESEARCH \\ 1050 Massachusetts Avenue \\ Cambridge, MA 02138 \\ October 2007
}

This paper was prepared for the conference in honor of Joe Newhouse's 25 years of editing the Journal of Health Economics. I am grateful to Doug Norton for superb research assistance, and to Henry Aaron, Jonathan Skinner, the editors, three anonymous referees, and conference participants for helpful comments, and to the National Institutes on Aging for research support. The views expressed herein are those of the author(s) and do not necessarily reflect the views of the National Bureau of Economic Research.

(C) 2007 by David M. Cutler. All rights reserved. Short sections of text, not to exceed two paragraphs, may be quoted without explicit permission provided that full credit, including $\odot$ notice, is given to the source. 
The Lifetime Costs and Benefits of Medical Technology

David M. Cutler

NBER Working Paper No. 13478

October 2007

JEL No. I11

\begin{abstract}
$\underline{\text { ABSTRACT }}$
Measuring the lifetime costs and benefits of medical technologies is essential in evaluating technological change and determining the productivity of medical care. Using data on Medicare beneficiaries with a heart attack in the late 1980s and 17 years of follow up data, I evaluate the long-term costs and benefits of revascularization after a heart attack. I account for non-random selection into treatment with instrumental variables; following McClellan, McNeil, and Newhouse, the instrument is the differential distance to a hospital capable of providing revascularization. The results show that revascularization is associated with over 1 year of additional life expectancy, at a cost of about $\$ 40,000$. Revascularization, or other treatments correlated with it, appears to be highly cost-effective.
\end{abstract}

David M. Cutler

Department of Economics

Harvard University

1875 Cambridge Street

Cambridge, MA 02138

and NBER

dcutler@harvard.edu 
Technological change is the predominant reason for medical cost increases in the past half century. Studies of aggregate medical spending and of particular medical conditions show that at least half of all cost growth is a result of increased use of technology (Newhouse, 1992; Cutler and McClellan 2001).

But evaluating the short run cost of technology is not the only policy need. There are two other issues that also need to be considered. The first is the health benefits that result from technology. Medical technology may be expensive, but it might still be a good deal, if it extends the length or quality of life or otherwise results in positive social returns. Understanding cost-effectiveness is more important than understanding costs alone.

Even in the cost realm, short run costs are only a partial story. Medical advances applied in one year can lead to higher or lower spending in subsequent years. Costs subsequently may increase if people survive to spend more, or may fall if people live healthier lives and thus use less care. These downstream impacts of new technology need to be evaluated in addition to the up front costs. Indeed, it is possible for new technology to lower future spending, if the improved health that results from it offsets the increase in spending over the longer number of years.

In this paper, I consider the lifetime costs and benefits of medical technology. I first show theoretically how to measure the impact of medical technology on lifetime medical spending, and the long-run cost effectiveness of new technology. I then turn to a specific medical technology: therapeutic surgical care after a heart attack. In the aftermath of a heart attack, many people will receive bypass surgery or angioplasty 
(collectively termed revascularization) to restore blood flow to the heart. Each is expensive, and the value of each has been debated (Skinner, Staiger, and Fisher, 2007). I focus on the marginal value of receiving these intensive treatments.

The central empirical issue in evaluating the impact of any technology is the nonrandom selection of who receives the care. The sickest patients may not be strong enough to withstand revascularization, and the healthiest patients may not need it. Thus, the set of people receiving revascularization is not a random set of people with a heart attack. McClellan, McNeil, and Newhouse (1994) account for this by instrumenting for receipt of the technology, using the differential distance from the patient's zip code of residence to a hospital capable of providing the technology as the instrument. ${ }^{1}$ I follow the same strategy in this paper.

The advantage that I bring to these previous efforts is the ability to analyze outcomes over longer-periods of time. McClellan, McNeil, and Newhouse (1994) used only four years of follow-up data on MI patients. I take advantage of the greater elapsed time since their study was completed and use 17 years of data on MI cohorts. This gives me a more complete lifetime spending and survival history for Medicare beneficiaries who had an MI in the late 1980s.

Like McClellan, McNeil, and Newhouse (1994), I show that people who receive a revascularization procedure have lower mortality in the first day after the MI than those not receiving revascularization. This may not be a result of revascularization; most revascularizations are not performed that rapidly. Rather, it probably reflects selection or other correlated treatments. However, this initial mortality benefit disappears by one year

\footnotetext{
${ }^{1}$ Chandra and Staiger (2007) follow this strategy as well. They use data fro the mid-1990s but have only one year of mortality follow-up.
} 
after the MI; mortality is higher for the revascularization group at that point. In subsequent years, revascularization is associated with reduced mortality, with an increase in their survival rate of 5 percentage points after 3 years and 12 percentage points after a decade. Even 17 years after the MI, the survival benefit is 5 percentage points.

While revascularization extends survival, it does not save money. Receiving revascularization is associated with increased spending of about $\$ 40,000$ after a decade, of which 60 percent comes in the immediate aftermath of the MI. Still, the costs are small relative to the benefits. I estimate that the cost of revascularization is about $\$ 33,000$ per year of extra life.

In contrast to these results for revascularization, I find very small survival benefits of being admitted to a high volume hospital, and significantly greater spending. Survival rates in high volume hospitals are 2 percentage points higher in the period just after the MI, and half a percent higher after that. The overall survival benefit is .07 years, at a cumulative cost of nearly $\$ 10,000$ higher. The cost-effectiveness is thus $\$ 144,000$ per year.

There are two possible interpretations of these results. If one believes the instrumental variables, they suggest that intensive medical care in the aftermath of an MI is highly cost effective, even if it doesn't save money. It is possible, however, that the instrument is picking up other aspects of being admitted to a hospital with revascularization capability. Revascularization hospitals may be better than hospitals without revascularization capability because they provide better medical management during the admission, because they are better at post-admission follow-up, or because people come to them for treatment of other conditions in subsequent years, and receive 
better care at that point. Adopting this formulation, the estimates suggest lower absolute mortality benefit, but about the same cost-effectiveness $-\$ 17,000$ per year of additional life.

The paper is structured as follows. The first section considers the theoretical impact of medical technology on lifetime costs. The second section describes the case study I consider. The third section presents the data. The fourth and fifth sections present the results, and the last section discusses the implications.

\section{The Lifetime Impact of Medical Technology}

Imagine that a new medical technology is developed to treat people with a particular condition. A natural desire is to estimate the costs and benefits of the new technology. Short-run costs and health impacts are relatively easy to measure, if one has the right data. One looks at how spending and health for people with the treatment compare to similar people without the treatment. The major issue in this comparison is econometric: how to separate out the effect of the treatment from the factors that make someone more or less likely to receive the treatment or from other treatments correlated with the one under study. I return to this below.

But short-run costs and benefits are not the only concern. A treatment provided in one year may have impacts on health and medical care received down the road, and this may increase or decrease the cost-effectiveness of the therapy. Consider a technology $s$ with upfront costs in year t of $m^{*}$. I denote $I_{s}$ as an indicator for whether the technology is provided. The technology affects health in the future, so $H_{t+k}=H_{t+k}\left(I_{s}\right)$, where $H_{t+k}$ is health in year $t+k$. Since future spending is related to future health status, this will have 
impacts on future costs: $m_{t+k}=m_{t+k}\left(H_{t+k}\right)$. Substituting the recursive equations, the present value of lifetime medical spending is given by:

$$
\text { Spending }=m_{t}\left(I_{s}\right)+\sum_{k=1}^{\infty}(1+r)^{-k} m_{t+k}\left(H_{t+k}\left(I_{s}\right)\right)
$$

where $r$ is the discount rate. The first term in equation (1) is the direct cost of the technology. The second term is the indirect cost, operating through subsequent health status.

One can imagine situations where the second term is positive or negative. A life saving intervention increases future costs. Without the intervention, the person dies and future spending is zero. With the intervention, the person survives. Regardless of the health state of the survivor, there will be some medical spending. Interventions that reduce disability, in contrast, could lower lifetime spending. If the intervention results in fewer lifetime years spent disabled, or if death occurs at a later age and is thus cheaper, the total costs of caring for the person may decline. This latter point is particularly important given the very high spending at the end of life. Over one-quarter of Medicare spending is in the last year of life, so that interventions that make death cheaper could come with significant savings.

Table 1 show the magnitude of this possible effect, using data from Hoover et al. (2002) on deaths in the mid-1990s. Average spending in the last year of life is over $\$ 37,000$, compared to $\$ 7,000$ for people who do not die. Total end of life costs are relatively constant by age. ${ }^{2}$ Medicare costs, however, decline with age at death. A Medicare beneficiary dying at age 85 or older spends nearly $\$ 10,000$ less in the last year

\footnotetext{
${ }^{2}$ One qualification to this finding is that people who die at older ages are more likely to have been in nursing homes, and at least some of the nursing home cost is for residential services. Thus, the medical component of total end of life costs is probably falling with age.
} 
of life than a beneficiary dying between 65 and 74. Partly, this is because older people die of different diseases than younger people (pneumonia versus cancer, for example). In addition, physicians are generally less aggressive in treating older people than treating younger people. Since a good part of non-Medicare spending is paid for by the individual (out-of-pocket payments for nursing homes, for example), it is likely that total public spending declines with age at death.

To see what this implies, consider an intervention that has a 10 percent chance of extending the life of an 80 year old by ten years. The additional ten year survival lowers Medicare end of life costs by perhaps $\$ 8,000$, or $\$ 800$ for the population as a whole. Thus, the cost of the intervention could be as high as $\$ 800$ without raising lifetime spending. ${ }^{3}$ This is not a huge amount, but it is not trivial either.

The counterpart to spending is health benefits. Consider a particular normalization of $H_{t^{+}}$, scaled between 0 (death) and 1 (perfect health). Quality adjusted life expectancy is given by:

$$
Q A L E=\sum_{k=0}^{\infty}(1+r)^{-k} H_{t+k}\left(I_{s}\right)
$$

Equation (2) shows the same discount rate for quality as for costs, but this needn't be the case (Gold et al., 1996).

The cost-effectiveness of the technology can be found by taking the ratio of changes in equations (1) and (2): ${ }^{4}$

$$
\text { Cost }- \text { Effectiveness }=\frac{m_{t}^{*}+\sum_{k=1}^{\infty}(1+r)^{-k}\left(d m_{t+k} / d H_{t+k}\right) \Delta H_{t+k}}{\sum_{k=0}^{\infty}(1+r)^{-k} \Delta H_{t+k}}
$$

\footnotetext{
${ }^{3}$ For simplicity, I ignore discounting in this example.

4 See Meltzer (1997) for a similar derivation.
} 
The numerator of equation (3) is the impact of the technology on medical spending, the sum of current and (discounted) future costs. The denominator is the change in qualityadjusted life expectancy.

An important issue in the analysis of lifetime costs and benefits is the treatment of downstream interventions. Consider a specific example. Suppose that bypass surgery keeps people alive and that some of those kept alive develop cancer. The cancer may be more common in bypass surgery survivors (for example, smokers are differentially saved) or independent. How does the treatment of cancer affect the cost-effectiveness of bypass surgery?

Much of the literature argues for omitting the future costs of unrelated diseases, arguing that this is irrelevant for considering the particular therapy under question (Gold et al., 1996). Garber and Phelps (1997) justify this in a model without savings, though Meltzer argues that these costs need to be included if consumption is decided in an intertemporal framework. Lee (forthcoming) suggests a distinction between future medical costs, which ought to be included, and future non-medical costs, which ought not to be included. In my analysis, I consider the present value of future medical spending, but not non-medical spending.

Even when future costs are included, the importance of future diseases makes the evaluation of equation (3) complex. Consider again the example of bypass surgery and downstream cancer. Equation (3) might show a high cost effectiveness ratio (that is, large costs relative to the benefits) either because bypass surgery care is not very effective relative to its cost, or because cancer care is wasteful. If the latter is the case, 
one could make the wrong decision and decide not to provide bypass surgery, when the right decision is to provide bypass surgery but constrain cancer care.

There are some circumstances in which downstream costs will not be important. If cancer is equally likely to affect people who have bypass surgery and not, and the impact of cancer treatment is the same for people who have and have not received bypass surgery, then cancer costs and benefits will be the same for the bypass surgery group and the non-bypass surgery group, and the evaluation of bypass surgery will not be affected by subsequent cancer care. Neither of these assumptions is likely to be true, however. Any intervention that affects mortality will almost certainly affect the probability of contracting other diseases. Further, by affecting the subsequent path of health, bypass surgery may make future cancer care more or less likely to be successful.

In the absence of these assumptions, equation (3) can be interpreted as a weighted average of the costs and benefits of bypass surgery and all the subsequent conditions that are correlated with receiving bypass surgery. As a result, one cannot necessarily attribute the estimate cost-effectiveness ratio as a causal statement about bypass surgery. But even in this setting, it answers an important factual question: is it worth it to provide bypass surgery, given how people are treated on average as they age? I discuss the interpretation of the findings in more depth below.

\section{The AMI Example}

Most cost-effectiveness evaluations simulate the life course with and without the disease and use those simulations to estimate lifetime costs and benefits. In some cases, 
however, these data can be estimated directly, using longitudinal records on people with a particular condition. I follow this latter path with the example of heart attacks.

Understanding a little medicine is helpful for following the analysis. A heart attack occurs when the arteries supplying blood to the heart become occluded. Restoring blood flow to the heart is the primary therapeutic goal for someone presenting with an MI. This can be accomplished with medications, or through invasive surgical procedures. Such procedures begin with a cardiac catheterization, a diagnostic procedure to measure blood flow to the heart. Depending on the results, the cardiologist may decide to treat the patient medically, to perform coronary artery bypass grafting (CABG), or to use angioplasty (PCI), now done almost exclusively with stents. Bypass surgery and angioplasty together are referred to as revascularization. I consider the lifetime costs and benefits of revascularization.

Because of its intensity, Medicare pays more for invasive care than for medical management. Average costs in the 90 days after the MI are about $\$ 10,000$ for patients who receive medical management, $\$ 15,000$ for patients who are catheterized with no further procedure, $\$ 40,000$ for patients who go on to receive CABG, and $\$ 20,000$ for patients who receive an angioplasty. These high dollar amounts make understanding the lifetime costs and benefits of revascularization particularly important.

There is significant debate about the value of these procedures in the literature. Clinical studies generally show that bypass surgery and primary angioplasty (angioplasty done within the first hours of the MI) are associated with improvements in survival (Yusuf et al., 1994; Keeley et al., 2003), though non-primary angioplasty (done after the first few hours) is not (Hochman et al., 2006). Clinical trials may not be relevant to real 
world application, however, particularly for complex surgical interventions such as cardiac interventions.

Existing literature analyzing data from actual practice has reached conflicting conclusions. Studies of large changes in procedure use generally show significant health benefits. Cutler and McClellan (2001) argue from aggregate data that advances in intensive treatments from 1984 to 1998 increased one-year survival by about 10 percentage points and increased life expectancy by nearly one year, at a cost of only $\$ 10,000$ - through Skinner, Stagier, and Fisher (2007) show that this progress stopped after 1998. McClellan and Newhouse (1995) show that hospitals that open cardiac catheterization labs have 9 percentage points lower one year mortality rates; the cost per one year survivor is $\$ 70,000$. Similarly, Stukel et al. (2005) showed that areas that provided cardiac catheterization to more patients had 10 percent lower morality than areas with lower cardiac catheterization rates (roughly 4 percentage points with a 40 percent one year mortality rate), though the difference narrowed in areas providing good medical management.

There is more controversy about the benefits accruing to the marginal patient receiving intensive therapy. Using data from 1987, McClellan, McNeil, and Newhouse (1994) estimate that people receiving cardiac catheterization because they lived closer to a facility providing it experienced 5 percentage points lower mortality a year after the MI, but most of this gain occurred during the first day, when catheterization would not be expected to provide significant benefit. Chandra and Staiger (2007) repeat the analysis using data from the mid-1990s and estimate a 14 percentage point mortality advantage to cardiac catheterization. The reconciliation between these studies is not entirely clear. 
Beyond analysis of specific therapies, evidence shows clearly that not all care is worth it. Skinner, Staiger, and Fisher (2007) document that areas with greater increases in spending on heart attacks did not experience greater outcomes - though spending increases are not very highly correlated with increased use of intensive procedures. All of these considerations make an analysis of longer term outcomes important.

\section{Data}

The data I employ come from Medicare records. I mirror as much as possible the work of McClellan, McNeil, and Newhouse (hereafter MMN). MMN use data on all Medicare beneficiaries admitted to a hospital with a heart attack in 1987. I do not have access to the complete set of MI patients, but I construct a similar sample using a 20 percent sample of all Medicare beneficiaries. Specifically, I sample all beneficiaries who were admitted to a hospital with a heart attack in 1986, 1987, or 1988 and use the same omission criteria as MMN to narrow down to non-repeat MIs. ${ }^{5}$ The final sample size is 124,950 patients.

The advantage of my data is the additional years that have passed since the MMN analysis. Where they are constrained to 4 year outcomes, I have complete histories through 2005. I thus construct 17 year survival and cost experiences for people with an AMI in 1986-88. By 17 years after the MI, nearly every Medicare beneficiary with a heart attack will have died.

\footnotetext{
${ }^{5}$ I exclude people with an MI in the prior 365 days, people who were in the hospital for fewer than three days, other than those who died or were transferred, and people living more than 100 miles from the hospital of initial admission. For the cost analysis, I exclude people who joined an HMO at any time after their MI, since spending data in HMOs are not reliably reported. Given the sickness of these patients, this is not a large share of cases.
} 
Data on procedure use are available in the Medicare claims. In my primary results, I follow the bulk of the literature and examine receipt of revascularization procedure within 90 days of the MI. This captures time for the initial survival therapy to be applied, and for others to receive procedures after a few weeks. I show sensitivity results with a shorter window of time until the revascularization - 7 days and 30 days.

In the late 1980s, about two-thirds of revascularization was bypass surgery; today, angioplasty is more common. In my sample, about 30 percent of angioplasties were performed in the first day of the heart attack, and 70 percent were after that. Since many of the first day angioplasties probably occurred many hours after the MI, the best way to view the sample is as predominantly non-primary angioplasty.

Spending data are also from Medicare claims records. Part A records are available for the entire 20 percent sample of Medicare beneficiaries. Part B data are only available for 5 percent of beneficiaries, however. To make spending as complete as possible, I use the smaller number of observations in the spending regressions $(\mathrm{N}=29,988)$. The results using Part A data only for this simple are generally similar to those from the larger sample; this is not surprising given the large sample sizes.

More troubling for the spending data is that they reflect only Medicare covered services; the Federal government does not match Medicare beneficiaries to non-Medicare spending. Without any obvious source of non-Medicare data, I examine only Medicare spending. All dollar amounts are adjusted to 2006 dollars using the GDP deflator.

Revascularization is one factor that may affect health outcomes, but there are others as well. Medical management of heart attacks involves a variety of medications (aspirin, beta-blockers, ACE inhibitors, and others) along with specialized facilities such 
as coronary care units. The Medicare data do not contain information on use of medications, so I cannot examine how they influence survival and costs. One proxy for the general quality of heart attack care is the number of heart attack patients the hospital treated. Providers with more experience have better outcomes than those with less experience (Huckman and Pisano, 2006). Following MMN, I define a hospital as high volume if it admits at least 75 Medicare patients with heart attacks in the relevant year. ${ }^{6}$

The Medicare data have information on mortality but not quality of life. I thus measure health only by whether the person survived. Given the high mortality rate for people over 65 with an MI - 40 percent will die within one year - survival is an important measure of overall health.

I relate survival and cumulative medical spending over $k$ years to three sets of factors: demographic and health controls $(\mathbf{X})$, a dummy variable for whether the patient received a revascularization procedure (REVASC), and a dummy variable for whether the patient was admitted to a high volume hospital (HIGH VOLUME). The equations are of the form:

$$
\begin{aligned}
& \text { Spending }_{\mathrm{i}}(\mathrm{k})=\mathbf{X}_{\mathrm{i}} \alpha^{\mathbf{k}}+\alpha_{1}{ }^{\mathrm{k}} * \operatorname{REVASC}_{\mathrm{i}}+\alpha_{2}{ }^{\mathrm{k}} * \text { HIGH VOLUME } \\
& \text { Mortality }_{\mathrm{i}}(\mathrm{k})=\boldsymbol{X}_{\mathrm{i}} \beta^{\mathbf{k}}+\beta_{1}{ }^{\mathrm{k}} * \operatorname{REVASC}_{\mathrm{i}}+\beta_{2}{ }^{\mathrm{k}} * \text { HIGH VOLUME } \\
&
\end{aligned}
$$

By estimating these equations over different intervals, $k$, we can trace out the impact of revascularization and admission to a high volume hospital on lifetime health and medical spending.

The control variables (X) in equations (4) and (5) are in several categories. Basic demographics include age by sex dummy variables (65-69, 70-74, 75-79, 80-84, 85+) and

\footnotetext{
${ }^{6}$ Since I have a 20 percent sample of patients, I count hospitals as high volume if they have 15 admissions in the year.
} 
dummies for black and other race. I also include dummies for the year of the MI: 1986, 1987, or 1988. To capture the time from the MI until entering the medical system, I include distance to the nearest hospital and a dummy for rural residence. Finally, to control for underlying health status, I include dummies for 24 comorbid conditions noted as secondary diagnoses on the MI admission or on a hospital admission in the prior year ${ }^{7}$ as well as total Medicare spending in the year prior to the MI.

Several econometric issues arise in considering equations (4) and (5). Equation (4) relates spending linearly to receipt of revascularization or admission to a high volume hospital. Since entry into the sample is conditional on hospitalization, there is no need for a two-part model. ${ }^{8}$ But there is an issue about whether spending is significantly rightskewed, and if so whether a log transformation should be used. In practice, results from logarithmic specifications gave very similar results. ${ }^{9}$ For simplicity, I report the results for the level of spending.

In the survival equation (5), an alternative to the cumulative survival function is to estimate a hazard model for death in any year. By allowing for separate coefficients by year, I am effectively estimating a survival function with an unconstrained baseline. I present the cumulative survival function and variations in that function based on receipt of revascularization and admission to a high volume institution.

The major issue in estimating equations (4) and (5) is the endogeneity of revascularization and high volume hospital admission. Conditional on having a heart

\footnotetext{
${ }^{7}$ The list includes the categories from Elixhauser et al. (1998): congestive heart failure, valvular disease, pulmonary circulation disorders, peripheral vascular disorders, paralysis, other neurological disorders, chronic pulmonary disease, uncomplicated diabetes, complicated diabetes, renal failure, liver disease, peptic ulcer disease, HIV-AIDS, lymphoma, metastatic cancer, solid tumor without metastasis, rheumatoid arthritis, coagulopathy, weight loss, fluid and electrolyte disorders, blood loss anemia, deficiency anemia, alcohol abuse, and psychoses.

${ }^{8}$ Effectively, the first part of the model - use of any medical care - is the same for everyone.

${ }^{9} \mathrm{I}$ have also experimented with trimming large outliers in spending, again with similar impacts.
} 
attack, very sick and very healthy patients are each less likely to receive intensive therapies. The natural solution is instrumental variables. I return to this below, after presenting OLS results.

\section{The Lifetime Consequences of AMI Treatment}

I begin with OLS estimates of the return to revascularization and being admitted to a high volume hospital. These serve as a benchmark for the more appropriate instrumental variables. Figure 1 shows OLS estimates of cumulative mortality for various years after the heart attack. The scale for the revascularization coefficients is on the left hand side of the graph, and the scale for the high volume hospital coefficients is on the right hand side. In each case the estimates are negative for all time periods revascularization and admission to a high volume hospital always lower mortality. But the revascularization coefficients in particular seem too large to be plausible. The results suggest that revascularization reduces mortality by over 18 percent in the first 90 days and 20 percent after one year. Clinical trials rarely show an impact of surgery that is this large or that immediate. It seems clear that patient selection into treatment is nonrandom.

The solution to the endogeneity issue in MMN, which I follow, is to use instrumental variables. MMN argue that the "differential distance” to a hospital capable of performing the indicated procedure - the distance to the nearest revascularization hospital minus the distance to the nearest hospital of any type - is a good instrument for actual receipt of the procedure. This is true because patients are generally taken to the 
nearest hospital after an MI, and where one is admitted affects what is done - even several months later.

There are two important criteria for differential distance to be a good instrument. First, it needs to be the case that patients who are more likely to benefit from invasive treatments do not select their residential location based on distance to high-tech medical care. There is no way to test this directly, though like MMN I show that most covariates are balanced above and below the median differential distance.

The second criterion is that differential distance not be correlated with other treatments affecting outcomes. For example, if hospitals that provide revascularization are also better at providing aspirin at admission, at managing post-acute follow-up, or at treating subsequent illnesses years later, the instrumental variables estimates will overstate the importance of revascularization. This too is difficult to test, and worrisome because of the importance of a variety of other important therapies for AMI survival. I return to the interpretation of the instrumental variable estimates below.

The first stage equations are given by:

$$
\begin{aligned}
& \text { REVASC }_{\mathrm{i}}=\mathbf{X}_{\mathrm{i}} \gamma+\gamma_{1} * \text { REVASC DIFFERENTIAL-DISTANCE }{ }_{\mathrm{i}}+v_{\mathrm{i}} \\
& \text { HIGH VOLUME }_{\mathrm{i}}=\mathbf{X}_{\mathrm{i}} \boldsymbol{\delta}+\delta_{1} * \text { HIGH VOLUME DIFFERENTIAL-DISTANCE } \\
& \mathrm{i}
\end{aligned}
$$

To form differential distance, I need to code hospitals as capable of providing revascularization or not. Survey data on technological capabilities often have some error. To judge true revascularization capability, I see if the hospital performed at least 2 procedures on Medicare beneficiaries in the indicated year. ${ }^{10}$ This variable is allowed to change in the three year panel, though change is not rapid. ${ }^{11}$

\footnotetext{
${ }^{10}$ Requiring two procedures reduces the importance of solitary coding errors.

${ }^{11}$ About 2 percent of hospitals acquire revascularization capability over the time period.
} 
Receipt of a revascularization procedure is a binary variable, as is mortality. In the absence of instrumental variables, the appropriate estimation of the mortality regression would be non-linear, for example a probit or logit specification. In IV models, however, non-linear equations are problematic (Newey, 1990). I thus estimate all of the models using linear probability equations.

Table 2 reports summary information on the differential distance measures. In the 1986-88 period, the average differential distance to a hospital with revascularization capability is 8 miles, and the average differential distance to a high volume hospital is 2 miles. There is a good deal of heterogeneity in the differential distance measures. The $25^{\text {th }}$ percentile differential distance is 1 mile for revascularization and 0 miles for a high volume hospital. The $75^{\text {th }}$ percentile is 30 miles for revascularization and 20 miles for high volume.

While not everyone who is revascularized is admitted to a high volume hospital, high volume hospitals are far more likely to have revascularization capability. The correlation between differential distance for revascularization and high volume hospital is .640. I estimate the model with both variables included. In specification tests, I included each variable separately. The impact of revascularization or admission to a high volume hospital is similar with and without the other variable included.

As noted above, one criterion for a valid instrument is that patients do not choose which hospital to live near on the basis of health status. We can partially test this by looking at how observable risk factors are related to differential distance. Table 3 shows differences in demographic characteristics of the population by differential distance to a hospital with revascularization capability, and a high volume of admissions. In each 
case, I cut the data about at the median. The first rows report differences in demographics. Because of the sample size, equality of the means for people who live closer and farther from the indicated hospitals is frequently rejected. In most cases, however, the substantive differences are not large. The major exception is urban or rural residence. Many of those with high differential distance to a revascularization or high volume hospital live in rural areas. To account for this, I include controls for distance to nearest hospital and rural residence in the regression.

The next rows show that differential distance is associated with hospital of admission. People living below the median distance to a revascularization hospital are 38 percentage points more likely to be initially admitted to a hospital capable of providing revascularization than are people who live farther away. The difference in high volume admission based on above and below median distance to a high volume facility is 51 percentage points.

These differences in where people are admitted translate into differences in how they are treated. People who live closer to a revascularization hospital are 3 percentage points more likely to receive a revascularization procedure than are people who live farther away. Interestingly, living closer to a high volume hospital is not associated with increased likelihood of being revascularized.

The next rows report cumulative mortality rates at different intervals after the MI: one day, 180 days, 1 year, 5 years, 10 years, and 17 years (the longest time period with complete data in the sample). As in MMN, there is a large difference in mortality in favor of those living closer to a revascularization hospital. However, the pattern is nonlinear. In the first day after the MI admission, mortality rates are 1.1 percentage points 
lower for people living closer to a revascularization hospital. Given the infrequency of primary angioplasty in this time period, it is unlikely that this reflects the impact of revascularization. Rather, it likely reflects unmeasured differences in patient characteristics, or other forms of therapy provided by hospitals that are capable of providing revascularization, such as greater use of aspirin or thrombolytic drugs.

Beyond one day, the gap in mortality narrows so that by one year after the MI, there is no improvement in survival associated with living near a revascularization hospital. Even the percentage difference ( 0.4 percentage points) is smaller. After the one year interval, however, the gap in mortality again increases. By 10 years after the MI, people living closer to a revascularization hospital are 0.5 percent more likely to survive than those living farther away. This is true even with an 80 percent cumulative mortality rate. The difference is relatively constant through 17 years. It is more plausible that this reflects receipt of a revascularization procedure, although the case is not proven.

If one believes that the difference in mortality ten years after the MI reflects the receipt of the revascularization, one can use Table 3 to estimate the marginal impact of that therapy. The Wald estimate of the impact of revascularization on ten year survival is the mortality difference scaled by the difference in procedure receipt, or 17 percent (0.5/3.0). This is a large impact.

The impact of living near a high volume hospital follows a similar pattern. There is a large mortality benefit of living near such an institution (1.3 percent) one day after the MI. This might reflect better care provided by such institutions, or possibly selection of cases. That gap remains roughly constant for the first year after the MI, and then narrows considerably. By 10 years after the MI, the difference in mortality is 0.3 percent, 
and is only significant at the 10 percent level. Further, the Wald estimate of the impact of being admitted to a high volume hospital is much smaller - only 0.6 percent $(0.3 / 51)$.

The final set of rows shows the impact of differential distance on cumulative spending after the MI. Spending is total expenditures up to that year; people who die are included in the sample, with their costs up to death included. Spending is consistently higher for those living near a revascularization or high volume facility. The difference in costs is about $\$ 3,000$ in the 30 days after the MI, and increases to $\$ 9,000$ by a decade later. These differences in costs are sizeable. The cost differences reflect two factors: more care provided to patients who live closer to hospitals with revascularization capability, and increased prices that Medicare pays for such hospitals (assuming these are teaching hospitals or hospitals that care for a disproportionate share of the poor). Typically, studies of variation in medical spending attribute a greater share to what is done than the prices paid. But the vast number of outpatient claims makes an exact division difficult to determine.

Of course, there is power in explaining service use beyond just the single cut of above or below median differential distance. In the first stage of the IV estimation, I break the differential distance into 15 buckets (as in MMN): 0, <1 mile, 1-2 miles, 2-4 miles, 4-6 miles, 6-8 miles, 8-10 miles, 10-12 miles, 12-15 miles, 15-18 miles, 18-21 miles, 21-25 miles, 25-30 miles, 30-40 miles, and 40+ miles. Table 4 shows the first stage equations predicting receipt of revascularization or admission to a high volume hospital. $^{12}$ The coefficients are generally as expected. In virtually all cases, increases in

\footnotetext{
${ }^{12}$ In practice, both differential distance measures are used to predict each outcome. Controlling for differential distance to a revascularization facility, differential distance to a high volume hospital does not affect receipt of revascularization therapy. Similarly, differential distance to a revascularization hospital
} 
differential distance are associated with a reduced probability of receiving that type of care. In the case of revascularization, for example, a person living 15 or more miles away from a revascularization facility is 5 percentage points less likely to receive a revascularization than is a person whose nearest hospital is capable of providing revascularization. In the case of a high volume hospital, the differential distance impact is 74 percentage points at 15 miles.

Table 5 shows the second stage estimation results. For readability, the coefficients are graphed in Figure 2 (the impact on survival) and Figure 3 (the impact on costs). The non-distance covariates (not shown) are as expected. Older people, men, and people with more prior conditions are more likely to die than their opposites.

The impact of revascularization is broadly similar to the Wald estimates derived from Table 3. The marginal person receiving a revascularization is about 4 percentage points more likely to survive the first day after the MI than if the person did not receive a revascularization (although not statistically significantly). This gap narrows over time and even reverses by 1 year. At that time interval, people who received revascularization are 6 percentage points more likely to have died than people not receiving revascularization.

After one year, a new gap in survival develops, in favor of those receiving revascularization. By two years post-MI, people who receive a revascularization procedure are 3 percentage points more likely to be alive. After 7 years, the impact is 12 percentage points and is statistically significant. The gap remains about 12 percentage points through 12 years after the MI. As overall mortality increases, the gap narrows a 
bit. By 17 years after the MI, the mortality benefit for those receiving revascularization is 5 percentage points and is not statistically significant.

It is difficult to know what accounts for this survival pattern. It could be a real trend of treatment. Some patients will be saved by primary PTCA. Other patients might die during the revascularization procedure, or as a result of complications from it. ${ }^{13}$ Mortality could then decline as one-year survivors are at lower risk of recurrent episodes.

But selection of patients or correlated treatments is also a concern. MMN argue that the reduction in one-day mortality was likely due to treatments other than intensive surgical care that hospitals capable of providing that care also provide. McClellan and Newhouse (1987) argue that this is true about hospitals opening catheterization labs as well, suggesting the treatments are cardiac ones. If one believes that these other factors are important but are fully accounted for by the one-day survival difference, the subsequent 8 percentage point reduction in mortality after the first day (or 14 percent reduction from one year) truly reflects the impact of revascularization.

Correlated treatments might be a concern after the MI as well. It may be that hospitals that provide revascularization are also better at post-acute follow-up - greater attention to diet and exercise, or an increased use of medications to prevent recurrent MIs. The Medicare data do not have evidence on this; these treatments are generally pharmaceuticals, and outpatient pharmaceuticals were not covered by Medicare at that time. Other evidence suggests that revascularization hospitals are unlikely to be superior in providing this care, however. Chandra and Staiger (2007) show that areas with higher cardiac catheterization rates in the mid-1990s were less likely to provide valuable

\footnotetext{
${ }^{13}$ Restenosis, or re-occlusion of the coronary arteries, was a relatively common outcome of angioplasty during this time period.
} 
medications to heart attack patients when they were inpatients. The evidence would have to be the opposite at the hospital level to explain the results here.

Alternatively, the correlated therapy might be provided years later. People who go to a hospital for an MI are likely to go there for other problems as well. Thus, cancers, broken hips, and pneumonias are more likely to be treated in these intensive hospitals. If quality is correlated across diseases, these hospitals might be better at other treatments as well. The possibility that care for conditions other than the heart attack explains the longer-term survival improvements could be tested with enough information on subsequent conditions and treatments received. This analysis would require a complex model of the range of medical conditions, however. Such a model does not now exist. As a crude proxy, the regressions presented above control for pre-existing conditions as of the MI. Exploring this possible correlation is a valuable subject for future research.

Figure 3 shows the impact of revascularization and admission to a high volume hospital on Medicare spending. Medicare spending is significantly higher for the revascularization group than the group not receiving revascularization. In the 90 days after the MI, the revascularization group spends $\$ 28,308$ more. This matches closely the mean reimbursement differential for revascularization therapy noted above, suggesting the estimate is plausible. Incremental spending rises to $\$ 30,149$ by one year after the MI and remains at that level for the next six years. It is possible that this relative constancy reflects the higher end of life costs for the non-revascularization patients. Those patients die sooner, and thus incur the higher costs of end of life care. After 7 years, the cost gap increases, to a level of about $\$ 40,000$ by year 10 . 
The impact of being admitted to a high volume hospital is significantly smaller than the impact of receiving revascularization. The mortality impact is nearly 2 percentage points in the first day (statistically significant), but then declines to 0.5 percentage points by two years (not statistically significant). It remains close to that level through the rest of the sample. Being admitted to a high volume hospital is associated with increased spending, with an amount that is increasing over time. The initial difference is about $\$ 2,000$, and rises to $\$ 10,000$ by year 13 .

\section{Alternative Specifications}

I have estimated a variety of alternative models to test the robustness of the basic IV results. I present some of these specification tests for the revascularization coefficients, since that therapy has the larger impact on survival and costs.

The first issue is the time frame in which revascularization is measured. While considering 90 day procedure rates is standard in the literature, extending the time frame reduces the discriminatory power of differential distance - since consultation with providers in the community will result in additional procedures being performed for those initially admitted to non-revascularization hospitals. A sharper test thus looks at care provided closer to the time of initial admission. To consider this, I estimate models for the impact of revascularization within 7 days and 30 days of the MI. The results are shown in the second and third rows of Table 6 (the first row repeats the results in Table 5, for convenience).

Narrowing the window for the revascularization has little quantitative impact on the findings. There is still a one day survival improvement for people receiving a 
catheterization, ranging between 3 and 4 percentage points. By one year after the MI, mortality is higher for the revascularization group, by 6 to 10 percentage points. Over the next few years, patients receiving revascularization fare better, with a mortality benefit of 11 to 12 percentage points after a decade and declining after that.

The costs associated with revascularization are somewhat smaller for revascularizations that occur closer in time to the MI. Relative to the $\$ 30,000$ additional cost in the first year for the baseline specification, the first year cost is $\$ 17,000$ for the group receiving revascularization in the first week after the MI, and \$26,000 for the group receiving revascularization within a month. This may reflect that patients who wait longer for revascularization are on average sicker.

The next rows separate the revascularization impact by urban and rural residence. Revascularization may have a different impact in urban and rural areas. Time to the hospital varies with urban/rural location, influencing how sick patients are when first treated. In addition, surgeons may have more experience with revascularization in urban areas, and thus better outcomes. As table 6 shows, survival benefits are significantly greater in urban areas than in rural ones. The increase in mortality in the first year is greater in rural areas than in urban ones. Further, the 10 year survival benefit is 16 percent in urban areas, while there is no survival benefit in rural areas.

The final specification I examine reformulates the problem to consider the issue of correlated treatments. As long as patients do not choose where to live on the basis of their potential benefits from intensive care, the regressions will accurately capture the impact of having been initially admitted to a hospital capable of performing revascularization. By instrumenting for initial admission to a revascularization hospital 
rather than just receiving a revascularization, I can estimate the impact of the full range of therapies associated with early adopters of revascularization technology.

These results are shown in the last row of Table 6 . The pattern of coefficients is generally similar to the estimates for revascularization, but the magnitudes are lower. Mortality for those initially admitted to a revascularization-capable hospital is higher after one year, but then declines in subsequent years. The gap is one percentage point after 6 years and remains there for most of the next decade. The similar qualitative pattern is encouraging. The lower quantitative magnitude is a natural product of the analysis, and can be seen most clearly in the revascularization columns of table 3 . The regression for receiving a revascularization attributes the half-percent or so better mortality profile for people living near revascularization hospitals to the 3 percentage point higher revascularization rates for those living closer to such facilities. In the regression for being admitted to a revascularization hospital, in contrast, the same mortality difference is instead attributed to the 38 percentage point difference in where people are admitted. The impact of admission is obviously smaller.

Corresponding to this smaller mortality impact is a lower cost associated with admission. Table 6 shows that cumulative spending is about $\$ 1,400$ higher for those admitted to a hospital capable of performing revascularization.

\section{Implications}

There are two ways to interpret the results in the previous section. The first is that they largely reflect the true impact of revascularization. Using the values presented, we can estimate the incremental lifetime cost-effectiveness of revascularization therapy. 
Standard lifetable methods indicate that the greater survival for the marginal patients receiving revascularization translates into 1.1 years of additional life expectancy. ${ }^{14}$ The cost of this gain is about $\$ 38,000$. Thus, the cost per year of life is $\$ 33,246$. Admission to a high volume hospital is substantially less cost effective. The increase in life expectancy is only 0.06 years, and the incremental cost is nearly $\$ 10,000$. The cost per year of life is thus $\$ 175,719$.

The value of a year of life is generally taken to be about $\$ 100,000$ (Cutler, 2004). That value typically assumes good quality of life; the quality here may not be as high. However, these calculations ignore any improvements in quality of life that may result from revascularization. For non-primary angioplasty in particular, that is a big part of the potential benefits. Thus, it is not clear whether accounting for quality would lead to more or less favorable cost-effectiveness ratios. Overall, it is virtually certain that revascularization after an MI is highly cost-effective.

The unresolved issue in this first interpretation is whether the benefits of revascularization flow from that therapy, or from receipt of other services that are correlated with admission to a hospital with revascularization capabilities. If it is the latter, the results reflect the current and future implications of an initial admission to a high-tech hospital, but not necessarily receipt of those procedures. In this case, the mortality benefit is smaller, but so are costs. The estimates in the last row of Table 6 translate into a benefit of .08 years at a cost of $\$ 1,389$, or $\$ 17,022$ per year of additional life. Care is clearly worth it, but which care is an open question.

\footnotetext{
${ }^{14}$ This assumes that people who survive 17 years all die in the next year. The 1.1 year survival improvement is not particularly sensitive to this assumption.
} 
The obvious issue is how these estimates compare to others in the literature. MMN do not estimate the cost of catheterization, but other studies do. As noted above, McClellan and Newhouse (1987) estimate that costs are about \$70,000 per patient surviving an additional year. Since the average heart attack survivor lives 5 years in our data, this is about $\$ 14,000$ per lifeyear. Cutler and McClellan (2001) use time series data to estimate a cost of about $\$ 10,000$ per additional year of life. The estimates are very close to what I present.

The biggest empirical puzzle raised by these results is the extent to which the improved outcomes reflect intensive treatment of the heart attack versus less intensive treatment, or treatment of other conditions. Without better treatment data and a detailed analysis of the full range of subsequent conditions, I cannot answer the question definitively. Separating out the impact of high tech care from other care is a topic worthy of future research. 


\section{References}

Chandra, Amitabh, and Douglas O. Staiger, "Productivity Spillovers in Health Care: Evidence from the Treatment of Heart Attacks", Journal of Political Economy, 2007, 115(1), 103-140.

Elixhauser, Anne, Claudia Steiner, D. Robert Harris, et al., "Comorbidity measures for use with administrative data,” Medical Care, 1998, 36(1), 8-27.

Garber, Alan M., and Charles E. Phelps, "Economic Foundations of CostEffectiveness Analysis”, Journal of Health Economics, 16, 1997, 1-33.

Gold, Marthe R., Joanna E. Siegel, Louise B. Russell, and Milton C. Weinstein, Cost Effectiveness in Health and Medicine, New York: Oxford University Press, 1996.

Hochman, Judith S., et al., "Coronary Intervention for Persistent Occlusion After Myocardial Infarction,” New England Journal of Medicine, 2006, 255:2395-2407.

Hoover, Donald R., Crystal, Stephen, Kumar, Rizie, Usha Sambamoorthi, Joel C. Cantoret, "Medical Expenditures During the Last Year of Life: Findings From the 19921996 Medicare Current Beneficiary Survey.” Health Services Research 2002, 37(6), 1625-1642.

Huckman, Robert S., and Gary P. Pisano. "The Firm Specificity of Individual Performance: Evidence from Cardiac Surgery." Management Science 2006, 52(4), 473488.

Keeley Ellen C., Judith A. Boura, Cindy L. Grines, “Primary angioplasty versus intravenous thrombolytic therapy for acute myocardial infarction: a quantitative review of 23 randomised trials,” Lancet 2003 Jan 4;361(9351):13-20.

Lee, Robert S., “Cost Effectiveness Analysis and Future Costs”, Journal of Health Economics, forthcoming.

McClellan, Mark B., Barbara McNeil, and Joseph P. Newhouse, "Does More Intensive Treatment of Acute Myocardial Infarction in the Elderly Reduce Mortality?” Journal of the American Medical Association. 1994;272(11):859-66

Meltzer, David, “Accounting for Future Costs in Medical Cost-Effectiveness Analysis,” Journal of Health Economics, 16, 1997, 33-64.

Newey, Whitney, “Efficient Instrumental Variables Estimation of Nonlinear Models,” Econometrica, 1990, 58(4), 809-837.

Newhouse, Joseph P., "Medical Care Costs: How Much Welfare Loss?" Journal of Economic Perspectives 1992, 6(3): 3-21. 
Skinner, Jonathan S., Douglas O. Staiger, and Elliott S. Fisher, "Is Technological Change in Medicine Always Worth It? The Case of Acute Myocardial Infarction", Health Affairs, 2006, 25, w34-w47.

Stuckel, Therese A., F. Lee Lucas, and David E. Wennberg, "Long-Term Outcomes of Regional Variations in Intensity of Invasive vs. Medical Management of Medicare Patients with Acute Myocardial Infarction”, JAMA, 2005, 293:1329-1337.

Yusuf, Salim et al., "Effect of Coronary Artery Bypass Graft Surgery on Survival: Overview of Ten-Year Results from Randomised Trials by the Coronary Artery Bypass Graft Trialists Collaboration," Lancet 344, no. 8922 (1994): 563-570 
Table 1: Average Medical Spending by Time Until Death

\begin{tabular}{lcc}
\hline & \multicolumn{2}{c}{ Time until death } \\
\cline { 2 - 3 } Payer and Age & $<12$ months & $>12$ months \\
\hline All Payers & & \\
Total & $\$ 37,561$ & $\$ 7,456$ \\
$65-74$ & 37,043 & 5,719 \\
$75-84$ & 38,529 & 7,832 \\
$85+$ & 36,985 & 13,895 \\
& & \\
Medicare & & \\
Total & $\$ 26,049$ & $\$ 3,786$ \\
$65-74$ & 27,832 & 3,247 \\
$75-84$ & 26,078 & 4,153 \\
$85+$ & 18,226 & 5,052 \\
& & \\
Non-Medicare & & \\
Total & $\$ 11,512$ & $\$ 3,670$ \\
$65-74$ & 9,211 & 2,472 \\
$75-84$ & 12,451 & 3,679 \\
$85+$ & 18,689 & 8,843 \\
\hline Note: Data are from Hoover et al. (2002). & The \\
average is adjusted to the age distribution of the \\
entire elderly population.
\end{tabular}


Table 2: Differential Distance Measures

\begin{tabular}{lcc}
\hline Measure & $\begin{array}{c}\text { Revascularization } \\
\text { hospital }\end{array}$ & $\begin{array}{c}\text { High volume } \\
\text { hospital }\end{array}$ \\
\hline Mean & 18.7 & 12.8 \\
$10^{\text {th }}$ \%ile & 0.0 & 0.0 \\
$25^{\text {th }}$ \%ile & 1.1 & 0.0 \\
$50^{\text {th }}$ \%ile & 7.8 & 1.9 \\
$75^{\text {th }}$ \%ile & 29.9 & 19.7 \\
$90^{\text {th }}$ \%ile & 51.3 & 44.4 \\
Correlations & & \\
Revasc hospital & 1.000 & --- \\
High volume hospital & .640 & 1.000 \\
\hline
\end{tabular}

Note: Hospitals are counted as having the capacity to perform revascularization if they do at least 2 procedures in the year in question. A high volume hospital is one with at least 15 admissions for MI in the year. 
Table 3: Differences in Patient Characteristics by Differential Distance Measures

\begin{tabular}{|c|c|c|c|c|c|c|}
\hline \multirow{2}{*}{ Characteristic } & \multicolumn{3}{|c|}{ Revascularization } & \multicolumn{3}{|c|}{ High Volume } \\
\hline & $<8$ miles & $>8$ miles & p-value & $<2$ miles & $>2$ miles & p-value \\
\hline \multicolumn{7}{|l|}{ Demographics } \\
\hline Average age & 76.2 & 76.1 & .072 & 76.2 & 76.1 & .349 \\
\hline Percent male & $49 \%$ & $52 \%$ & $<.001$ & $49 \%$ & $51 \%$ & $<.001$ \\
\hline Percent black & $7 \%$ & $4 \%$ & $<.001$ & $6 \%$ & $5 \%$ & $<.001$ \\
\hline $\begin{array}{l}\text { Percent other race / } \\
\text { unknown }\end{array}$ & $1.2 \%$ & $0.8 \%$ & $<.001$ & $0.9 \%$ & $1.1 \%$ & .026 \\
\hline Percent rural & $4 \%$ & $59 \%$ & $<.001$ & $11 \%$ & $52 \%$ & $<.001$ \\
\hline Prior year spending & $\$ 3,124$ & $\$ 2,442$ & $<.001$ & $\$ 3,035$ & $\$ 2,530$ & $<.001$ \\
\hline \multicolumn{7}{|c|}{ Hospital of initial admission } \\
\hline Revasc hospital & $47 \%$ & $9 \%$ & $<.001$ & $35 \%$ & $21 \%$ & $<.001$ \\
\hline High volume hospital & $65 \%$ & $36 \%$ & $<.001$ & $80 \%$ & $29 \%$ & $<.001$ \\
\hline \multicolumn{7}{|l|}{ Procedure receipt } \\
\hline Cath Within 90 & $26 \%$ & $21 \%$ & $<.001$ & $24 \%$ & $24 \%$ & .354 \\
\hline CABG within 90 & $9 \%$ & $7 \%$ & $<.001$ & $8 \%$ & $8 \%$ & .252 \\
\hline PTCA within 90 & $6 \%$ & $4 \%$ & $<.001$ & $5 \%$ & $5 \%$ & .057 \\
\hline Revasc within 90 & $14 \%$ & $11 \%$ & $<.001$ & $13 \%$ & $13 \%$ & .957 \\
\hline \multicolumn{7}{|l|}{ Cumulative Mortality } \\
\hline 1 day & $7.8 \%$ & $8.9 \%$ & $<.001$ & $7.7 \%$ & $9.0 \%$ & $<.001$ \\
\hline 180 Days & $34.6 \%$ & $35.3 \%$ & 0.007 & $34.2 \%$ & $35.8 \%$ & $<.001$ \\
\hline 1 year & $39.9 \%$ & $40.3 \%$ & 0.214 & $39.6 \%$ & $40.7 \%$ & $<.001$ \\
\hline 5 years & $62.5 \%$ & $62.9 \%$ & 0.244 & $62.5 \%$ & $62.9 \%$ & .094 \\
\hline 10 years & $79.8 \%$ & $80.3 \%$ & 0.041 & $79.9 \%$ & $80.2 \%$ & .090 \\
\hline 17 years & $93.4 \%$ & $93.7 \%$ & 0.008 & $93.4 \%$ & $93.7 \%$ & .006 \\
\hline \multicolumn{7}{|l|}{ Cumulative Costs } \\
\hline 30 Days & $\$ 16,045$ & $\$ 12,820$ & $<.001$ & $\$ 15,532$ & $\$ 13,290$ & $<.001$ \\
\hline 180 Days & $\$ 19,354$ & $\$ 15,386$ & $<.001$ & $\$ 21,531$ & $\$ 17,826$ & $<.001$ \\
\hline Year 1 & $\$ 26,441$ & $\$ 20,615$ & $<.001$ & $\$ 25,912$ & $\$ 21,059$ & $<.001$ \\
\hline Year 5 & $\$ 45,497$ & $\$ 36,043$ & $<.001$ & $\$ 44,909$ & $\$ 36,490$ & $<.001$ \\
\hline Year 10 & $\$ 60,986$ & $\$ 48,977$ & $<.001$ & $\$ 59,927$ & $\$ 49,861$ & $<.001$ \\
\hline Year 17 & $\$ 73,051$ & $\$ 59,800$ & $<.001$ & $\$ 72,029$ & $\$ 60,628$ & $<.001$ \\
\hline $\mathrm{N}$, Costs & 14,864 & 15,124 & - & 15,099 & 14,889 & - \\
\hline $\mathrm{N}$, All Other & 62,983 & 61,967 & - & 63,327 & 61,623 & - \\
\hline
\end{tabular}

Note: Cost sample excludes those enrolled in an HMO at any point after the MI 
Table 4: First Stage Instrumental Variable Results

\begin{tabular}{|c|c|c|}
\hline \multirow[b]{2}{*}{ Variable } & \multicolumn{2}{|c|}{ Outcome } \\
\hline & $\begin{array}{c}\text { Received } \\
\text { Revascularization }\end{array}$ & $\begin{array}{l}\text { Admitted to High } \\
\text { Volume Hospital }\end{array}$ \\
\hline \multicolumn{3}{|l|}{ Differential Distance } \\
\hline 0 mile & Reference & Reference \\
\hline$<1$ mile & $\begin{array}{c}-0.0112 \\
(-2.28)\end{array}$ & $\begin{array}{l}-0.1482 \\
(-28.58)\end{array}$ \\
\hline 1-2 miles & $\begin{array}{l}-0.0306 \\
(-6.90)\end{array}$ & $\begin{array}{l}-0.2684 \\
(-53.05)\end{array}$ \\
\hline 2-4 miles & $\begin{array}{c}-0.0294 \\
(-7.73)\end{array}$ & $\begin{array}{l}-0.3853 \\
(-84.96)\end{array}$ \\
\hline 4-6 miles & $\begin{array}{c}-0.0348 \\
(-8.12)\end{array}$ & $\begin{array}{l}-0.5187 \\
(-86.87)\end{array}$ \\
\hline $6-8$ miles & $\begin{array}{c}-0.0403 \\
(-7.83)\end{array}$ & $\begin{array}{l}-0.6159 \\
(-88.78)\end{array}$ \\
\hline 8-10 miles & $\begin{array}{l}-0.0482 \\
(-8.16)\end{array}$ & $\begin{array}{l}-0.6543 \\
(-81.43)\end{array}$ \\
\hline 10-12 miles & $\begin{array}{c}-0.0629 \\
(-9.71)\end{array}$ & $\begin{array}{l}-0.6999 \\
(-83.21)\end{array}$ \\
\hline $12-15$ miles & $\begin{array}{c}-0.0439 \\
(-8.06)\end{array}$ & $\begin{array}{c}-0.7449 \\
(-101.12)\end{array}$ \\
\hline $15-18$ miles & $\begin{array}{c}-0.0509 \\
(-8.78)\end{array}$ & $\begin{array}{l}-0.7423 \\
(-96.15)\end{array}$ \\
\hline 18-21 miles & $\begin{array}{l}-0.0592 \\
(-10.03)\end{array}$ & $\begin{array}{c}-0.7654 \\
(-100.53)\end{array}$ \\
\hline 21-25 miles & $\begin{array}{l}-0.0589 \\
(-10.88)\end{array}$ & $\begin{array}{c}-0.7855 \\
(-114.94)\end{array}$ \\
\hline 25-30 miles & $\begin{array}{l}-0.0584 \\
(-11.37)\end{array}$ & $\begin{array}{c}-0.7929 \\
(-118.07)\end{array}$ \\
\hline 30-40 miles & $\begin{array}{l}-0.0726 \\
(-16.06)\end{array}$ & $\begin{array}{c}-0.8079 \\
(-141.27)\end{array}$ \\
\hline $40+$ miles & $\begin{array}{l}-0.0799 \\
(-19.25)\end{array}$ & $\begin{array}{c}-0.8514 \\
(-180.61)\end{array}$ \\
\hline $\begin{array}{l}\text { Demographics, health } \\
\text { status controls }\end{array}$ & Yes & Yes \\
\hline $\mathrm{N}$ & 124,950 & 124,950 \\
\hline $\mathrm{R}^{2}$ & 0.077 & 0.434 \\
\hline
\end{tabular}

Note: The coefficients report the impact of differential distance to the relevant outcome on the probability of receiving that outcome (e.g., the impact of differential distance to a revascularization facility on receipt of revascularization). t-statistics are in parentheses. Each regression also includes differential distance to hospitals of the other type. Those coefficients are not reported. 
Table 5: Impact of Medical Care on Survival After an MI

\begin{tabular}{|c|c|c|c|c|}
\hline \multirow[b]{2}{*}{ Time After MI } & \multicolumn{2}{|c|}{ Revascularization } & \multicolumn{2}{|c|}{ High Volume Hospital } \\
\hline & Survival & Spending & Survival & Spending \\
\hline 1 day & $\begin{array}{l}-0.042 \\
(-1.08)\end{array}$ & - & $\begin{array}{c}-0.0192 \\
(-6.84)\end{array}$ & - \\
\hline 7 days & $\begin{array}{l}-0.020 \\
(-0.38)\end{array}$ & - & $\begin{array}{c}-0.0224 \\
(-5.80)\end{array}$ & - \\
\hline 30 days & $\begin{array}{l}-0.029 \\
(-0.47)\end{array}$ & $\begin{array}{c}\$ 24,544 \\
(4.84)\end{array}$ & $\begin{array}{c}-0.0195 \\
(-4.46)\end{array}$ & $\begin{array}{c}\$ 1,688 \\
(4.53)\end{array}$ \\
\hline 90 Days & $\begin{array}{l}-0.004 \\
(-0.06)\end{array}$ & $\begin{array}{c}\$ 28,308 \\
(4.57)\end{array}$ & $\begin{array}{c}-0.0185 \\
(-4.02)\end{array}$ & $\begin{array}{c}\$ 2,301 \\
(5.07)\end{array}$ \\
\hline 180 days & $\begin{array}{l}0.053 \\
(0.81)\end{array}$ & $\begin{array}{c}\$ 28,593 \\
(4.14)\end{array}$ & $\begin{array}{c}-0.0152 \\
(-3.20)\end{array}$ & $\begin{array}{c}\$ 3,152 \\
(6.22)\end{array}$ \\
\hline 1 year & $\begin{array}{l}0.061 \\
(0.91)\end{array}$ & $\begin{array}{c}\$ 30,149 \\
(3.28)\end{array}$ & $\begin{array}{c}-0.0097 \\
(-2.02)\end{array}$ & $\begin{array}{c}\$ 4,065 \\
(6.04)\end{array}$ \\
\hline 2 years & $\begin{array}{l}-0.029 \\
(-0.44)\end{array}$ & $\begin{array}{c}\$ 27,339 \\
(2.52)\end{array}$ & $\begin{array}{c}-0.0055 \\
(-1.13)\end{array}$ & $\begin{array}{c}\$ 5,300 \\
(6.65)\end{array}$ \\
\hline 3 years & $\begin{array}{l}-0.067 \\
(-1.02)\end{array}$ & $\begin{array}{c}\$ 25,919 \\
(2.16)\end{array}$ & $\begin{array}{c}-0.0049 \\
(-1.04)\end{array}$ & $\begin{array}{c}\$ 5,993 \\
(6.81)\end{array}$ \\
\hline 4 years & $\begin{array}{l}-0.043 \\
(-0.66)\end{array}$ & $\begin{array}{c}\$ 26,820 \\
(2.07)\end{array}$ & $\begin{array}{c}-0.0014 \\
(-0.30)\end{array}$ & $\begin{array}{c}\$ 6,560 \\
(6.90)\end{array}$ \\
\hline 5 years & $\begin{array}{l}-0.106 \\
(-1.68)\end{array}$ & $\begin{array}{c}\$ 27,517 \\
(1.99)\end{array}$ & $\begin{array}{c}-0.0053 \\
(-1.16)\end{array}$ & $\begin{array}{c}\$ 7,296 \\
(7.18)\end{array}$ \\
\hline 6 years & $\begin{array}{l}-0.118 \\
(-1.94)\end{array}$ & $\begin{array}{c}\$ 29,662 \\
(2.03)\end{array}$ & $\begin{array}{c}-0.0050 \\
(-1.13)\end{array}$ & $\begin{array}{c}\$ 7,659 \\
(7.15)\end{array}$ \\
\hline 7 years & $\begin{array}{l}-0.119 \\
(-2.02)\end{array}$ & $\begin{array}{c}\$ 31,090 \\
(2.03)\end{array}$ & $\begin{array}{c}-0.0048 \\
(-1.12)\end{array}$ & $\begin{array}{c}\$ 7,953 \\
(7.07)\end{array}$ \\
\hline 8 years & $\begin{array}{l}-0.108 \\
(-1.89)\end{array}$ & $\begin{array}{c}\$ 32,919 \\
(2.05)\end{array}$ & $\begin{array}{c}-0.0042 \\
(-1.02)\end{array}$ & $\begin{array}{c}\$ 7,982 \\
(6.79)\end{array}$ \\
\hline 9 years & $\begin{array}{l}-0.111 \\
(-2.03)\end{array}$ & $\begin{array}{c}\$ 36,961 \\
(2.21)\end{array}$ & $\begin{array}{c}-0.0058 \\
(-1.47)\end{array}$ & $\begin{array}{r}\$ 8,087 \\
(6.59)\end{array}$ \\
\hline 10 years & $\begin{array}{l}-0.119 \\
(-2.28)\end{array}$ & $\begin{array}{c}\$ 38,028 \\
(2.16)\end{array}$ & $\begin{array}{c}-0.0073 \\
(-1.95)\end{array}$ & $\begin{array}{c}\$ 8,314 \\
(6.45)\end{array}$ \\
\hline 11 years & $\begin{array}{l}-0.113 \\
(-2.27)\end{array}$ & $\begin{array}{c}\$ 38,191 \\
(2.08)\end{array}$ & $\begin{array}{c}-0.0061 \\
(-1.70)\end{array}$ & $\begin{array}{c}\$ 8,532 \\
(6.33)\end{array}$ \\
\hline 12 years & $\begin{array}{l}-0.120 \\
(-2.55)\end{array}$ & $\begin{array}{c}\$ 40,804 \\
(2.13)\end{array}$ & $\begin{array}{c}-0.0088 \\
(-2.59)\end{array}$ & $\begin{array}{c}\$ 9,002 \\
(6.40)\end{array}$ \\
\hline 13 years & $\begin{array}{l}-0.074 \\
(-1.68)\end{array}$ & $\begin{array}{c}\$ 38,079 \\
(1.91)\end{array}$ & $\begin{array}{c}-0.0060 \\
(-1.88)\end{array}$ & $\begin{array}{c}\$ 9,161 \\
(6.26)\end{array}$ \\
\hline 14 years & $\begin{array}{l}-0.064 \\
(-1.55)\end{array}$ & $\begin{array}{c}\$ 38,708 \\
(1.89)\end{array}$ & $\begin{array}{c}-0.0061 \\
(-2.03)\end{array}$ & $\begin{array}{c}\$ 9,671 \\
6.44)\end{array}$ \\
\hline 15 years & $\begin{array}{l}-0.047 \\
(-1.21)\end{array}$ & $\begin{array}{c}\$ 36,758 \\
(1.75)\end{array}$ & $\begin{array}{c}-0.0053 \\
(-1.90)\end{array}$ & $\begin{array}{c}\$ 9,524 \\
(6.19)\end{array}$ \\
\hline 16 years & $\begin{array}{l}-0.041 \\
(-1.15)\end{array}$ & $\begin{array}{c}\$ 37,200 \\
(1.75)\end{array}$ & $\begin{array}{c}-0.0060 \\
(-2.31)\end{array}$ & $\begin{array}{c}\$ 9,599 \\
(6.14)\end{array}$ \\
\hline 17 years & $\begin{array}{l}-0.051 \\
(-1.52)\end{array}$ & $\begin{array}{c}\$ 37,990 \\
(1.76) \\
\end{array}$ & $\begin{array}{c}-0.0068 \\
(-2.83) \\
\end{array}$ & $\begin{array}{c}\$ 9,770 \\
(6.17) \\
\end{array}$ \\
\hline
\end{tabular}

Note: Each cell is a separate regression of either cumulative mortality or spending. All regressions include controls for age/sex, race, distance to the nearest hospital, prior year spending, and 24 conditions. t-statistics are in parentheses. 
Table 6: Alternative Specifications of Impact of Revascularization on Mortality and Costs

\begin{tabular}{|c|c|c|c|c|c|c|c|c|c|}
\hline \multirow[b]{2}{*}{ Specification } & \multicolumn{5}{|c|}{ Mortality } & \multicolumn{4}{|c|}{ Costs } \\
\hline & 1 day & 90 days & 1 year & 10 years & 17 years & 90 days & 1 year & 10 years & 17 years \\
\hline Baseline & $\begin{array}{l}-0.042 \\
(-1.08)\end{array}$ & $\begin{array}{l}-0.004 \\
(-0.06)\end{array}$ & $\begin{array}{l}0.061 \\
(0.91)\end{array}$ & $\begin{array}{l}-0.119 \\
(-2.28)\end{array}$ & $\begin{array}{l}-0.051 \\
(-1.52)\end{array}$ & $\begin{array}{c}\$ 28,308 \\
(4.57)\end{array}$ & $\begin{array}{c}\$ 30,149 \\
(3.28)\end{array}$ & $\begin{array}{c}\$ 38,028 \\
(2.16)\end{array}$ & $\begin{array}{c}\$ 37,990 \\
(1.76)\end{array}$ \\
\hline \multicolumn{10}{|c|}{ Timing of Revascularization } \\
\hline 7 day revasc & $\begin{array}{l}-0.027 \\
(-0.63)\end{array}$ & $\begin{array}{l}0.019 \\
(0.28)\end{array}$ & $\begin{array}{l}0.095 \\
(1.31)\end{array}$ & $\begin{array}{l}-0.110 \\
(-1.92)\end{array}$ & $\begin{array}{l}-0.031 \\
(-0.84)\end{array}$ & $\begin{array}{c}\$ 19,382 \\
(2.64)\end{array}$ & $\begin{array}{c}\$ 16,844 \\
(1.61)\end{array}$ & $\begin{array}{c}\$ 19,443 \\
(0.98)\end{array}$ & $\begin{array}{c}\$ 16,872 \\
(0.69)\end{array}$ \\
\hline 30 day revasc & $\begin{array}{l}-0.036 \\
(-0.97)\end{array}$ & $\begin{array}{c}0.000 \\
(-0.01)\end{array}$ & $\begin{array}{l}0.061 \\
(0.95)\end{array}$ & $\begin{array}{l}-0.113 \\
(-2.22)\end{array}$ & $\begin{array}{l}-0.042 \\
(-1.31)\end{array}$ & $\begin{array}{c}\$ 25,346 \\
(3.84)\end{array}$ & $\begin{array}{c}\$ 25,961 \\
(2.69)\end{array}$ & $\begin{array}{c}\$ 31,517 \\
(1.72)\end{array}$ & $\begin{array}{c}\$ 33,264 \\
(1.48)\end{array}$ \\
\hline \multicolumn{10}{|c|}{ Urban-Rural Residence } \\
\hline Urban & $\begin{array}{l}-0.033 \\
(-0.81)\end{array}$ & $\begin{array}{l}-0.029 \\
(0.42)\end{array}$ & $\begin{array}{l}0.036 \\
(0.72)\end{array}$ & $\begin{array}{l}-0.164 \\
(-2.93)\end{array}$ & $\begin{array}{l}-0.065 \\
(0.036)\end{array}$ & $\begin{array}{l}\$ 23,159 \\
(3.11)\end{array}$ & $\begin{array}{l}\$ 21,268 \\
(1.91)\end{array}$ & $\begin{array}{l}\$ 28,205 \\
(1.38)\end{array}$ & $\begin{array}{c}\$ 32,379 \\
(1.31)\end{array}$ \\
\hline Rural & $\begin{array}{l}-0.071 \\
(-0.78)\end{array}$ & $\begin{array}{l}0.036 \\
(0.25)\end{array}$ & $\begin{array}{l}0.088 \\
(0.58)\end{array}$ & $\begin{array}{c}0.004 \\
(0.035)\end{array}$ & $\begin{array}{l}-0.002 \\
(-0.02)\end{array}$ & $\begin{array}{c}\$ 23,691 \\
(3.83)\end{array}$ & $\begin{array}{c}\$ 24,343 \\
(2.89)\end{array}$ & $\begin{array}{c}\$ 48,950 \\
(2.23)\end{array}$ & $\begin{array}{c}\$ 55,828 \\
(2.10)\end{array}$ \\
\hline \multicolumn{10}{|c|}{ Instrument for Initial Admission to High-Tech Hospital } \\
\hline $\begin{array}{l}\text { High tech } \\
\text { hospital admit }\end{array}$ & $\begin{array}{l}-0.0003 \\
(-0.09) \\
\end{array}$ & $\begin{array}{r}0.0027 \\
(0.46) \\
\end{array}$ & $\begin{array}{l}0.0077 \\
(1.27) \\
\end{array}$ & $\begin{array}{c}-0.0096 \\
(-2.00) \\
\end{array}$ & $\begin{array}{c}-0.0020 \\
(-0.64)\end{array}$ & $\begin{array}{c}\$ 1,408 \\
(2.23) \\
\end{array}$ & $\begin{array}{l}\$ 1,150 \\
(1.28)\end{array}$ & $\begin{array}{l}\$ 1,287 \\
(0.76)\end{array}$ & $\begin{array}{c}\$ 1,389 \\
(0.67) \\
\end{array}$ \\
\hline
\end{tabular}


Figure 1: OLS Estimates of the Impact of Revascularization and High Volume Hospital Admission on Cumulative Mortality

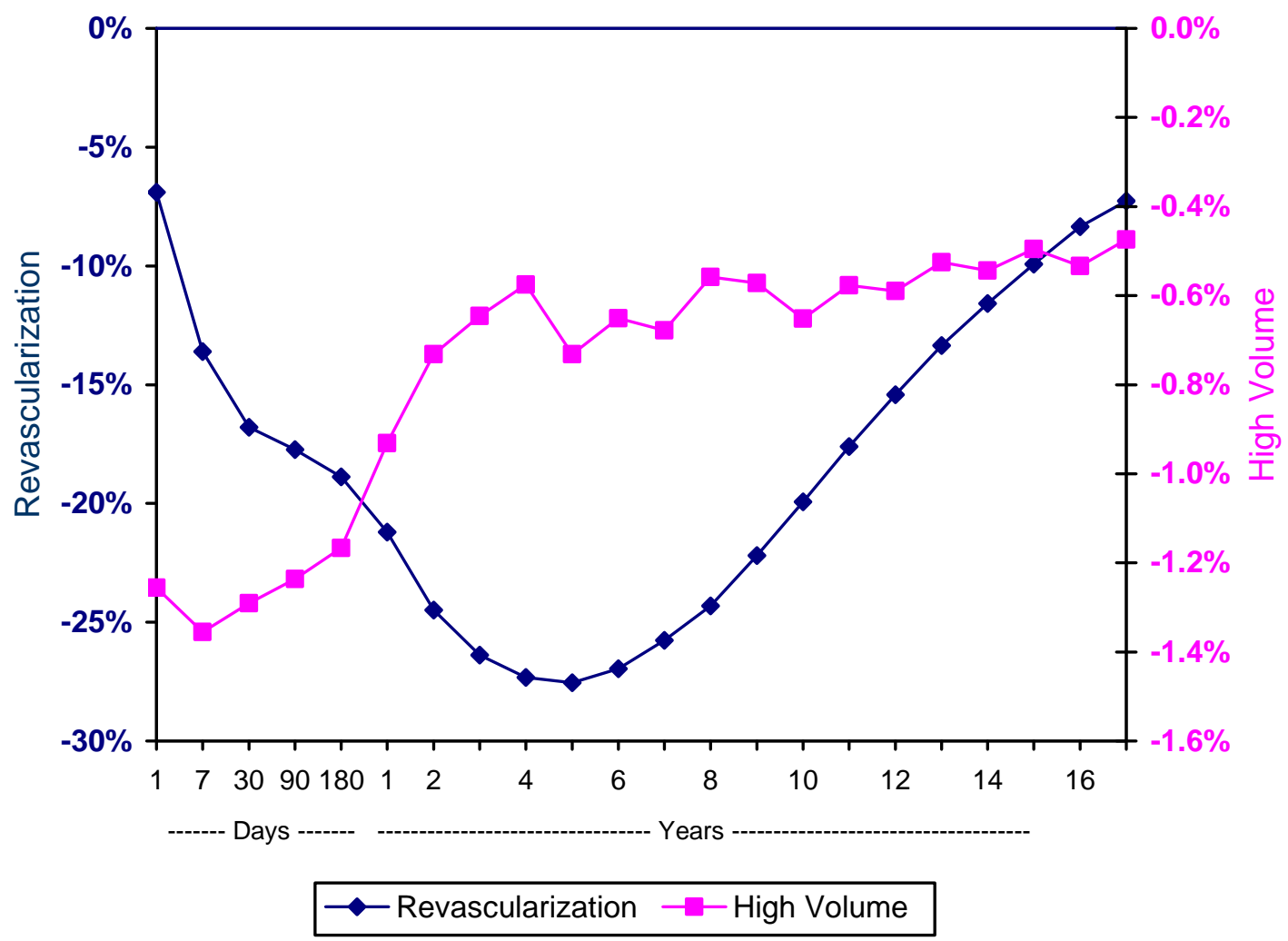


Figure 2: IV Estimates of the Impact of Revascularization and High Volume Hospital Admission on Cumulative Mortality

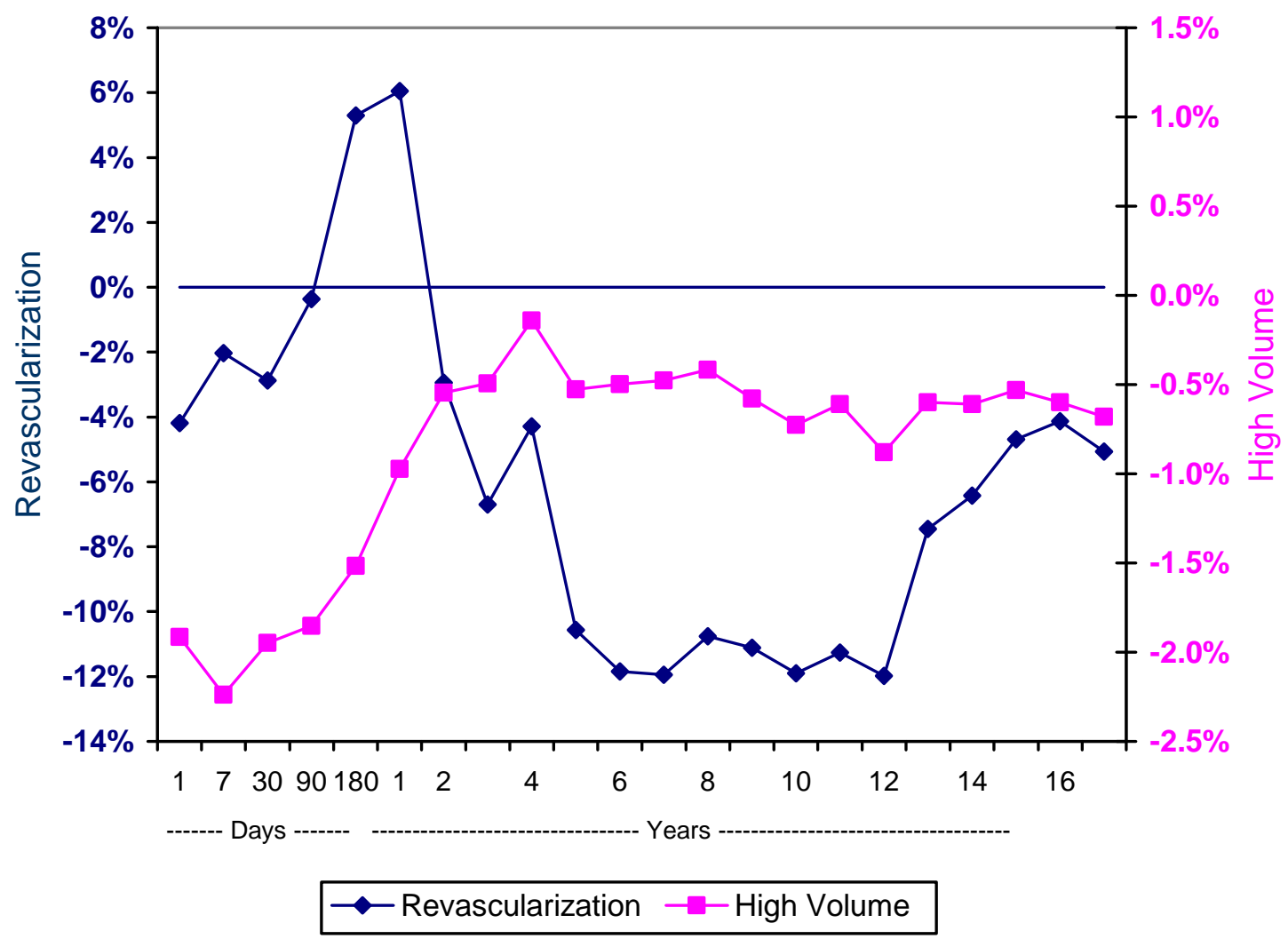


Figure 3: IV Estimates of the Impact of Revascularization and High Volume Hospital Admission on Cumulative Spending

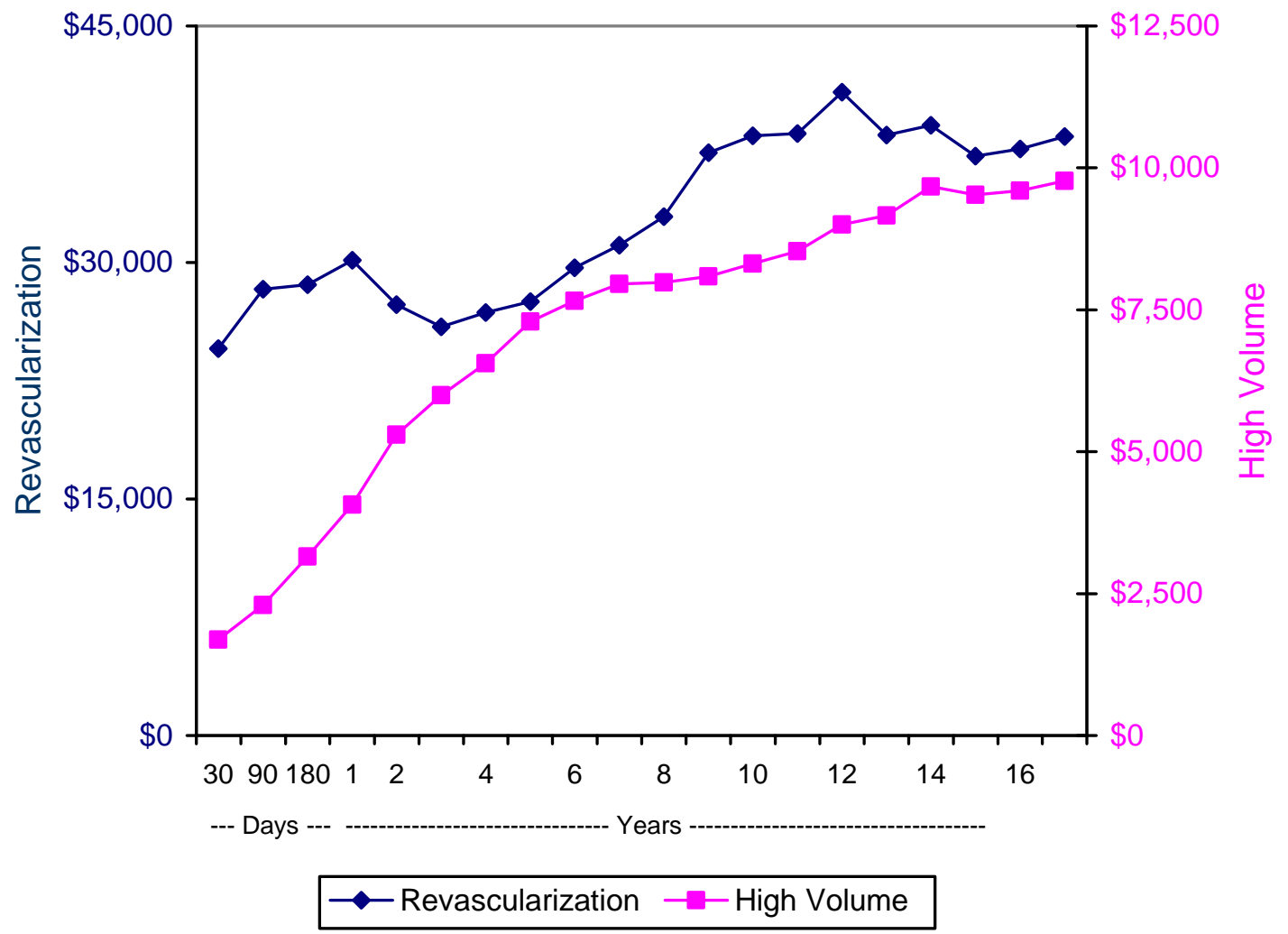

